\title{
TRAIL-R1-targeted chimeric antigen receptor T cells exhibit dual antitumor effects
}

\author{
AiShun Jin ${ }^{1}$, Yaru Nai ${ }^{1}$, Li Du ${ }^{1}$, Meiying Shen ${ }^{2}$, Tingting Li $^{1}$, Jingjing Huang ${ }^{1}$, xiaojian \\ $\mathrm{Han}^{1}$, Feiyang $\mathrm{Luo}^{1}$, and Da Pang${ }^{2}$ \\ ${ }^{1}$ Chongqing Medical University \\ ${ }^{2}$ Harbin Medical University Cancer Hospital
}

May 24, 2021

\begin{abstract}
Tumor necrosis factor-related apoptosis-inducing ligand receptor 1 (TRAIL-R1) has limited expression in normal tissues but highly expression in a broad range of tumors, making it an attractive target for cancer immunotherapy. We have previously prepared a fully human monoclonal antibody targeting TRAIL-R1 (TR1419), which can specifically induce apoptosis in antigenpositive tumor cells. Here, we prepared the TR1419CAR-T cells using the single chain variable fragment (scFv) from TR1419, which were evaluated for the phenotypes and function. The TR1419CAR-T cells induced cytolysis of TRAIL-R1-positive tumor cells not only via activation of the death receptor-dependent apoptotic pathway, but also via T-cell mediated cytotoxicity.

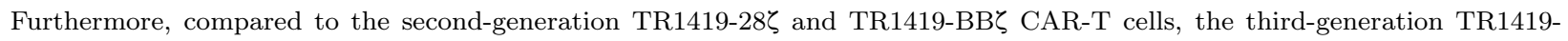
28BB $\zeta$ CAR-T cells had greater sensitivity to target antigen, exhibited a better proliferative ability, but showed slightly higher PD-1 expression after antigen stimulation. Altogether, TR1419CAR-T cells, especially TR1419-28BB CCAR-T cells could be a promising treatment strategy for TRAIL-R1 positive tumors.
\end{abstract}

\section{TRAIL-R1-targeted chimeric antigen receptor $\mathbf{T}$ cells exhibit dual antitumor effects}

Yaru Nai ${ }^{\mathrm{a}, 1}$, Li Du ${ }^{\mathrm{a}, 1}$, Meiying Shen ${ }^{\mathrm{b}}$, Tingting $\mathrm{Li}^{\mathrm{a}}$, Jingjing Huang ${ }^{\mathrm{a}}$, Xiaojian Han ${ }^{\mathrm{a}}$, Feiyang Luo ${ }^{\mathrm{a}}$, Da Pang $^{\mathrm{b}}$, Aishun Jin ${ }^{\mathrm{a},}{ }^{*}$

${ }^{a}$ Chongqing Key Laboratory of Basic and Translational Research of Tumor Immunology, Chongqing Medical University, Chongqing 400016, China

b Department of Breast Surgery, Harbin Medical University Cancer Hospital, Harbin 150081, China

* Corresponding authors at: Chongqing Key Laboratory of Basic and Translational Research of Tumor Immunology, Chongqing Medical University, No.1 Medical College Road, Yuzhong District, Chongqing 400016, People's Republic of China.

E-mail addresses : aishunjin@cqmu.edu.cn.

1 These authors contributed equally to this research.

\section{Abstract}

Tumor necrosis factor-related apoptosis-inducing ligand receptor 1 (TRAIL-R1) has limited expression in normal tissues but highly expression in a broad range of tumors, making it an attractive target for cancer immunotherapy. We have previously prepared a fully human monoclonal antibody targeting TRAIL-R1 $\left(\mathrm{TR} 1^{419}\right)$, which can specifically induce apoptosis in antigen-positive tumor cells. Here, we prepared the TR $1{ }^{419}$ CAR-T cells using the single chain variable fragment $(\mathrm{scFv})$ from $\mathrm{TR} 1^{419}$, which were evaluated 
for the phenotypes and function. The TR $1{ }^{419} \mathrm{CAR}-\mathrm{T}$ cells induced cytolysis of TRAIL-R1-positive tumor cells not only via activation of the death receptor-dependent apoptotic pathway, but also via T-cell mediated cytotoxicity. Furthermore, compared to the second-generation TR $1^{419}-28 \zeta$ and TR $1^{419}$-BB $\zeta$ CAR-T cells, the third-generation $\mathrm{TR} 1^{419}-28 \mathrm{BB} \zeta \mathrm{CAR}-\mathrm{T}$ cells had greater sensitivity to target antigen, exhibited a better proliferative ability, but showed slightly higher PD-1 expression after antigen stimulation. Altogether, TR $1{ }^{419}$ CAR-T cells, especially TR $1{ }^{419}-28 \mathrm{BB} \zeta \mathrm{CAR}-\mathrm{T}$ cells could be a promising treatment strategy for TRAIL-R1 positive tumors.

Key words: TRAIL-R1, CAR-T, Apoptosis, Cytotoxicity, Third-generation

\section{Introduction}

Chimeric antigen receptors (CARs) are synthetic molecules composed of an antigen recognition domain of single chain variable fragment $(\mathrm{scFv})$, a hinge region, a transmembrane domain, intracellular signaling

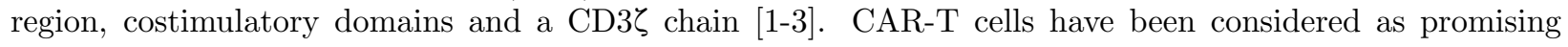
new modalities for adoptive cellular therapy [4]. Multiple clinical trials reported the CD19-target in the treatment of patient with malignancies $[5,6]$. However, there are still many encumbered challenges in solid tumor [7]. The key to the success of CAR-T cells therapy is the selection of an ideal target antigen, which should be expressed on the surface of cancer cells and shouldn't or little be expressed on normal cells $[8,9]$. Therefore, finding an ideal target for CAR-T cells is one of the most important tasks for successful CAR-T therapy in solid tumors [10]. Additionally, CAR co-stimulation domains play an essential role in promoting the expansion and antitumor of CAR-T cells [11-13]. It has been reported that the phenotypic and functional differences of the second and third generation CAR-T cells are related to the selection of target antigen and the design of scFv structure [14].

TRAIL is a member of the tumor necrosis family (TNF) superfamily that interacts with its death receptors (TRAIL-R1/TR1/DR4) and induces apoptosis in a wide range of cancer cell types but not in normal cells [15]. However, some clinical trials have shown that TRAIL has little antitumor efficacy [16]. Some cancer cells are resistant to TRAIL based therapies [17]. One reason is that TRAIL appeared not to induce effective aggregation of its cognate death receptor, leading to insufficient apoptosis of some tumor cells [18]. To overcome this shortcoming, agonistic antibodies that target TRAIL-R1 have been developed for clinical application. Previously, we developed a fully human monoclonal antibody (TR $1^{419}$ ) using the ISAAC ( immunospot array assay on a chip) technology and chimeric TransChromo (TC) mice with human immunoglobulin g and $x$ loci $[19,20]$. TR1 ${ }^{419}$ could strongly induce apoptosis in TR1 positive cancer cell lines in the presence of crosslinking antibodies [21]. Moreover, TR1 ${ }^{419}$ can enhance TRAIL-induced apoptosis by activation of caspase- 8 and upregulated expression of TR1 and increased phosphorylation of JNK $[22,23]$.

In the present study, we first generated third-generation TR1 ${ }^{419}-28 \mathrm{BB} \zeta \mathrm{CAR}-\mathrm{T}$ cells, which were shown to induce cytolysis of target tumor cells not only via TR1-mediated apoptosis but also via CAR signal-induced cytolysis. Furthermore, we compared which CARs structure was the most appropriate for scFv from TR1 ${ }^{419}$. The results showed that the third-generation TR $1^{419}-28 \mathrm{BB} \zeta$ CAR-T cells had higher sensitivity to target antigen, exhibited a better proliferative ability, but had a higher level of PD-1 expression after target antigen stimulation, compared to the second-generations TR $1^{419}-28 \zeta$ and TR $1^{419}-\mathrm{BB} \zeta$ CAR-T cells. This study suggests that TR $1{ }^{419} \mathrm{CAR}-\mathrm{T}$ cells could be a promising treatment strategy for TRAIL-R1 positive tumors, and the dual killing mechanism provides a novel optimizing strategy for other CARs design.

\section{Materials and methods}

\subsection{Plasmid construction and lentivirus preparation}

The target TR $1{ }^{419} \mathrm{CAR}$ consisted of $\mathrm{TR} 1^{419} \mathrm{scFv}$, CD28 or 4-1BB costimulatory domains, and CD3- $\zeta$ signaling domain $[24,25]$. They were obtained by overlap PCR amplification, PCR products were clone into lentivirus vector pWPXL and verified by enzymatic digestion and sequencing. To produce the lentivirus supernatant, $8 \times 10^{5}$ HEK-293T cells were plated in 6 -well. After $24 \mathrm{~h}, 293 \mathrm{~T}$ cells were transfected with pMD.2G encoding VSV-G envelope, pSPAX2 lentivirus plasmid, and the CAR-pWPXL plasmids by using 
xfect Transfection Reagent (Takara), according to the manufacturer's instructions. The lentivirus supernatants were collected and filtered with $0.45 \mu \mathrm{M}$ filter at $48 \mathrm{~h}$ after transfection.

\subsection{Cell lines and cell culture conditions}

SW480, HCT116, K562 and huh7 were obtained from ATCC. Human Jurkat cell line was maintained in our laboratory. These cells were cultured in RPMI 1640 medium (Gibco, Invitrogen, Carlsbad, CA) supplemented with $10 \%$ fetal bovine serum (FBS) (Biological Industries, ISR). Human breast cancer cell lines MDA-MB231 and HS578T were obtained from ATCC and cultured in Dulbecco's modified Eagle medium (Gibco, Invitrogen, Carlsbad, CA) supplemented with 10\% fetal bovine serum (FBS) (Biological Industries, ISR). The HEK-293T cell lines were purchased from ATCC and maintained in complete growth medium (Gibco invitrogen), containing with 10\% fetal bovine serum (FBS) (Biological Industries, ISR), 2mM L-glutamine (Gibco, Invitrogen) and $1 \mathrm{mM}$ sodium pyruvate solution (Gibco, Invitrogen). All above cells were cultured in a humidified atmosphere containing $5 \% \mathrm{CO}_{2}$ at 37 .

\subsection{Human CAR-T cells generation}

Human peripheral blood mononuclear cells (PBMCs) samples were obtained from healthy donors according to the manufacturer's protocol. Written informed consents were obtained from all donors. PBMC were stimulated with anti-CD3/CD28 for $48 \mathrm{~h}$. Then, the activated $\mathrm{T}$ cells were infected with the CAR-encoding lentiviral supernatant. $24 \mathrm{~h}$ after lentiviral infection, the lentiviral supernatant was replaced with fresh medium containing RPMI-1640 and supplemented with 10\% FBS (Gibco), 200U/ml IL-2, 25 mM HEPPES, $55 \mu \mathrm{M} 2-\mathrm{M}, 100 \mathrm{U} / \mathrm{ml}$ penicillin and $100 \mu \mathrm{g} / \mathrm{ml}$ streptomycin. The infected $\mathrm{T}$ cells were cultured for 7 days.

\subsection{Flow cytometry}

For cell-surface staining, the lentivirus-infected $\mathrm{T}$ cells were harvested and washed with phosphate buffered saline (PBS) followed by incubation with $1 \mathrm{ug} / \mathrm{ml}$ recombinant protein TRIL-R1-Fc (R\&D Systems, Minneapolis, MN) at room temperature for $20 \mathrm{~min}$. After being washed, the cells were incubation with $1 \mathrm{ug} / \mathrm{ml}$ APC conjugated anti-human IgG secondary antibodies and other cocktail antibodies (Biolegend) at room temperature for $15 \mathrm{~min}$ in the dark. After being washed with PBS, the cells were analyzed with a BD celesta (BD Biosciences) software by flow cytometry. The following monoclonal antibodies were used with the indicated subtypes: APC-lableled human IgG-Fc (clone HP6017), Percy5.5-lableled anti-CD4 (clone RPA-T4), Alex700-lableled anti-CD8 (clone HIT8a), BV421-lableled anti-CCR7 (clone G043H7), PE-lableled antiCD45RO (clone UCHL1), AF488-lableled anti PD-1(clone EH12.2H7), BV605-lableled anti-LAG-3 (clone 11C3C65), BV785-lableled anti-TIM-3 (clone F38-2E2). All sample data analyzed was done on[?]10,000 events using the FlowJo V 10 data analysis software.

\subsection{Killing activity assay}

The ability of CAR-T cells to kill tumor cells was determined via Calcein AM (CAM, Dojindo) release-based

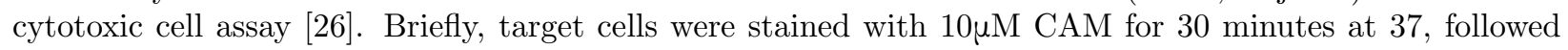
by terminating the reaction with addition of Durbe phosphate buffered saline without calcium (DPBS) buffer. The target tumor cells were washed five times with DPBS. Non-transduced T cells were used to normalize the percentage of CAR-positive cells. Then, CAR-T cells and target cells were plated in a 96-well microplate at various effector/target (E:T) ratios. After incubation for $6 \mathrm{~h}$ at $37{ }^{\circ} \mathrm{C}$, the $50 \mathrm{ul}$ supernatant were transferred to 96-black plates to measure fluorescence intensity (FI) at $485 \mathrm{~nm}$ excitation and 520 $\mathrm{nm}$ emission wavelengths. The percentage of cytotxicity was calculated according to the following formula: lysis $\%=($ test release-spontaneous release $) /($ maximal release-spontaneous release $) \times 100 \%$.

The ability of CAR-T cells to kill 293T cells was detected via Real Time Cell Analysis (RTCA, ACEA). One prior day to seeded approximately $1^{*} 10^{4} 293 \mathrm{~T}$ cells on 16 E-plate, the cells were grown to mid-logarithmic growth phase. Non-transduced T cells were used to normalize the percentage of CAR-positive cells, and CAR-T cells were added to the cultures at indicated effector-to-target ratio. RTCA DP analyzer was used to monitor real-time target cell growth, and the results were analyzed by RTCA software [27]. The percentage 
of cytotxicity was calculated according to the following formula: lysis $\%=[1-$ (experiments/empty culture) $]$ $\mathrm{x} 100 \%$.

\subsection{Enayme-linked immunosorbent assay}

The CAR-T cells and target tumor cells were co-cultured at various effector/target (E:T) ratios in a 96-well plate for $24 \mathrm{hr}$ at 37 . The culture supernatants were harvested and subjected to ELISA to detect INF- $\gamma$ and Granzyme B, according to the manufacturer's instructions. Every value represented the mean of triplicate wells.

\subsection{Tumor cells apoptosis assay}

CAR-T cells and target cells were incubated for $2 \mathrm{~h}$ at $37^{\circ} \mathrm{C}$, and target cell apoptosis was assayed using an Annexin V/7-AAD Apoptosis Detection Kit (Biolegend), according to the manufacturer's instructions. Target cell caspase-3 activity was detected used a caspase-3 activity detection assay kit (BD). In brief, the cells were washed twice with cold PBS, followed by fixing and permeabilizing in Cytofix/CytoPerm for 20 min on ice (BD Biosciences). Subsequent staining was performed with $1 \times$ PermWash as the staining and wash buffer and incubated for $15 \mathrm{~min}$ at room temperature. Washed cells were analyzed with a BD celesta (BD Biosciences) software by flow cytometry.

\subsection{Statistical analysis}

Statistical analyses in this study were performed with Graph Pad Prism software 8.0.2 version. Data are presented as the mean \pm SEM. When there were two experiment groups, Student's t-test was used or ANOVA analysis for multiple comparisons. $P<0.05$ were considered statistically significance.

\section{Results}

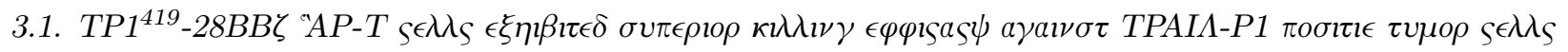

In order to generate $\mathrm{TR} 1^{419} \mathrm{CAR}-\mathrm{T}$ cells, we first constructed the lentivirus vector incorporating a CD28 and CD137 co-stimulatory domain, and CD3ל activation domain. The single-chain variable fragment ( $\mathrm{scFv}$ ) was derived from a fully human monoclonal antibody (TR1 ${ }^{419}$ ), which has high affinity and specificity for TRAIL-R1. We generated human TR1 ${ }^{419}-28 \mathrm{BB} \zeta$ CAR-T or mock-T cells by lentiviral transduction of PBMCs derived from healthy donors. The surface expression of CAR on the T cells was measured by flow cytometry. As shown in Fig. 1A, flow cytometric analysis confirmed that the frequency of CAR expression was $39.3 \%$. To characterize the phenotypes of the CAR-T cells, the cells were harvested for flow cytometric detection of CD45RA, CCR7, PD-1, LAG-3 and TIM-3 by day 7 after transfection. $45 \%-55 \%$ T cells were naïve $\mathrm{T}$ cells $\left(\mathrm{CCD} 45 \mathrm{RA}^{+} \mathrm{CCR} 7^{+}\right)$, and the proportions of the other three subtypes (central memory $\mathrm{T}$ cells, effector memory $\mathrm{T}$ cells, and effector $\mathrm{T}$ cells) were comparable (Fig.1B). No significant differences of immunoinhibitory molecule expression, PD-1, LAG-3 and TIM-3 were observed between TR1 ${ }^{419}-28 \mathrm{BB} \zeta$ CAR-T cells and mock $\mathrm{T}$ cells, indicating the phenotypes of $\mathrm{T}$ cells irrespective of gene transfection (Fig. $1 \mathrm{C})$

To determine whether TRAIL-R1 positive cancer cell lines were susceptible to TR1 ${ }^{419}$-28BB $\zeta$ CAR-T-cellmediated lysis in vitro, we performed cytotoxicity assays using engineered $\mathrm{T}$ cells as effector cells, and different cancer cells as target cells. The TRAIL-R1 expression in different cancer cells was validated by flow cytometry (Fig. S1). Compared with mock-transduced T cells, TR1 ${ }^{419}-28 \mathrm{BB} \zeta$ CAR-T cells displayed significantly higher specific killing activity against TRAIL-R1 positive SW480, HCT116 and MDA-MB-231 cells at all E:T ratios, and accompanied by an increased IFN- $\gamma$ and Granzyme B secretion (Fig. 1D-F). As for the TRAIL-R1 negative $293 \mathrm{~T}$ cells, TR1 ${ }^{419}-28 \mathrm{BB} \zeta$ CAR-T cells had no significant killing effect and secretion of effector cytokines, compared with the mock T cells (Fig. 1D-F). 

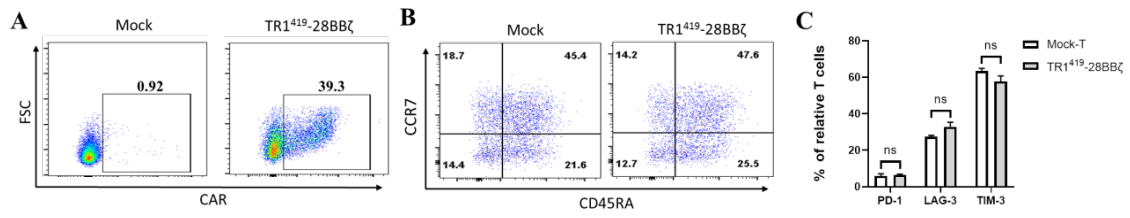

D
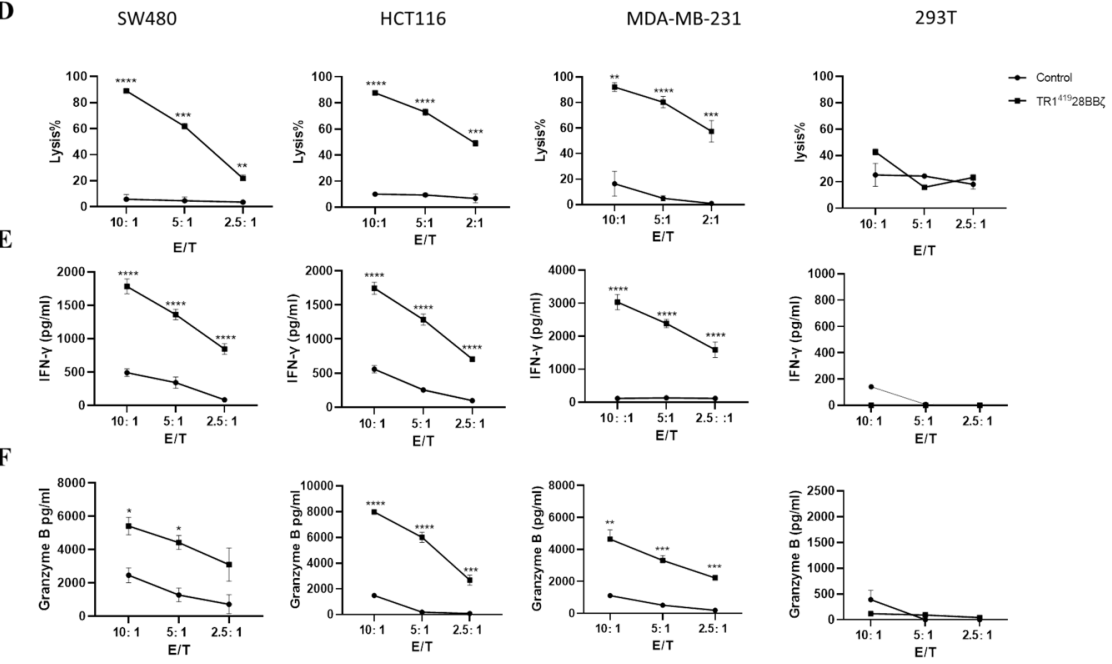

Fig.1.TR1 ${ }^{419}-28 B B \zeta$ CAR-T cells had specific killing to tumor cells. (A) CAR construct with humanized anti-TRAIL-R1 scFv, CD8a hinge, CD28 transmembrane domain and intracellular co-stimulatory domain,

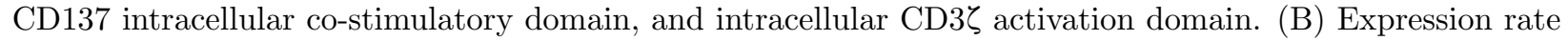
of the CAR on $\mathrm{T}$ cells was confirmed by flow cytometry on day 7 following lentiviral transfection. Mock $\mathrm{T}$ cells were served as a negative control. (C-D) Expression of inhibitory receptors and subtypes on CAR-T cells was examined by flow cytometry, CD45RA ${ }^{+} \mathrm{CCR} 7^{+}$: naïve $\mathrm{T}$ cells, $\mathrm{CD} 45 \mathrm{RA}{ }^{-} \mathrm{CCR} 7^{+}$: central memory $\mathrm{T}$ cells, CD45RA ${ }^{-} \mathrm{CCR} 7^{-}$: effector memory T cells, CD45RA ${ }^{+} \mathrm{CCR}^{-}$: effector T cells. (E) Cytotoxic activity of TR1 ${ }^{419}-28 \mathrm{BB} \zeta \mathrm{CAR}$ - or mock transduced T cells against TRAIL-R1 positive tumor cell lines. The effector cells were co-cultured for $6 \mathrm{~h}$ with target cells at E:T ratio of 10:1, 5:1 and 2.5:1, respectively. Cytotoxicity was determined by Calcein AM release-based cytotoxic cell assay. (F-G) IFN- $\gamma$ and Granzyme B production by TR1 ${ }^{419}-28 \mathrm{BB} \zeta$ CAR-T cells or mock-transduced T cells was detected by ELISA when co-cultured with the indicated cells for $24 \mathrm{~h}$. The analyses were performed using Students' t tests. Data reflected the mean \pm SEM of three separate experiments. ${ }^{*} p<0.05,{ }^{* *} p<0.01$ and ${ }^{* * *} p<0.001$.

\subsection{ScFv from TR $1^{419}$ CAR was proved to mediate tumor apoptosis in Jurkat cells}

To explore whether scFv from TR1 ${ }^{419}$ CAR could mediate tumor apoptosis through activation of the death receptor-dependent apoptotic pathway, we first constructed TR $1^{419}[?] \zeta$ lentivirus vector, which was composed

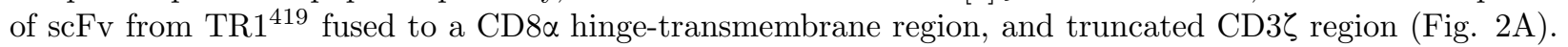
We generated TR1 $1^{419}-28 \mathrm{BB} \zeta$ or TR $1^{419}[?] \zeta$-jurkat cells by lentiviral transduction, and the surface expression of $\mathrm{scFv}$ on the jurkat cells was measured by flow cytometry (Fig. 2B). Then, the xCELLigence RTCA DP was adopted to determine whether TR $1^{419}-28 \mathrm{BB} \zeta$ or TR $1^{419}[?] \zeta$-jurkat cells could mediate tumor apoptosis. We have previously demonstrated with CD19-CAR that CAR-Jurkat cells have no ability to mediate the death of target antigen-positive tumor cells (Fig. S2). However, our results showed that TRAIL-R1-positive tumor cells were lysed by TR $1^{419}-28 \mathrm{BB} \zeta$-jurkat cells and TR ${ }^{419}[?] \zeta$-jurkat cells, and the specific cytotoxic effect can be blocked by the soluble target antigen TRAIL-R1 (Fig. 2C). 
Next, TR1 $1^{419}-28 \mathrm{BB} \zeta$-jurkat cells and TR1 $1^{419}[?] \zeta$-jurkat cells were co-incubated separately with SW480 cell lines for $2 \mathrm{~h}$ at a 1:1 ratio, then the expression of AnnexinV/7-AAD and caspase3 in SW480 cells was detected by flow cytometry. The percentages of 7-AAD - Annexin $\mathrm{V}^{+}$early $(25.3 \%)$ and 7 - $\mathrm{AAD}^{+}$Annexin $\mathrm{V}^{+}$late $(24.9 \%)$ apoptotic SW480 cells mediated by TR1 ${ }^{419}-28 \mathrm{BB} \zeta$-jurkat cells and TR1 ${ }^{419}[?] \zeta$-jurkat cells were significantly higher than the control (Fig. 2D). The percentages of Caspase $3^{+}$in SW480 cells mediated by TR1 $1^{419}-28 \mathrm{BB}$-jurkat cells and TR1 ${ }^{419}[$ ?] $]$-jurkat cells were also significantly higher than the control. Meanwhile, the soluble target antigen blocked $100 \%$ of the above killing activity. Collectively, these results suggested $\mathrm{scFv}$ from TR ${ }^{419}$ CAR can mediate TRAIL-R1-positive tumor apoptosis through activation of the death receptor-dependent apoptotic pathway.
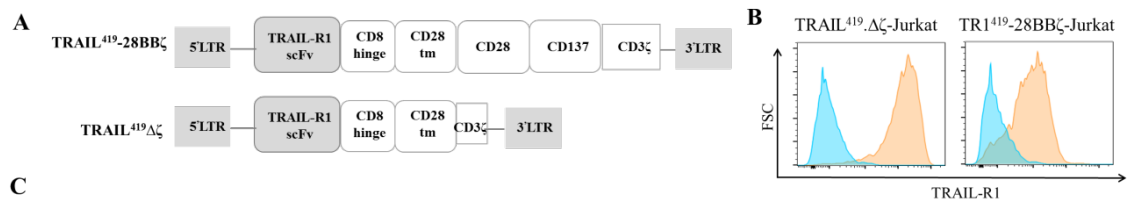

C
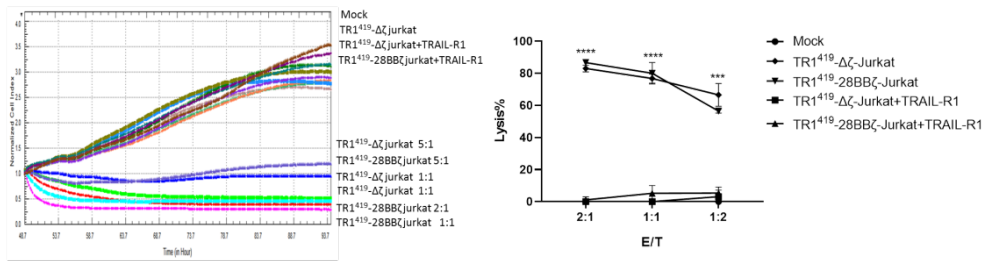

D
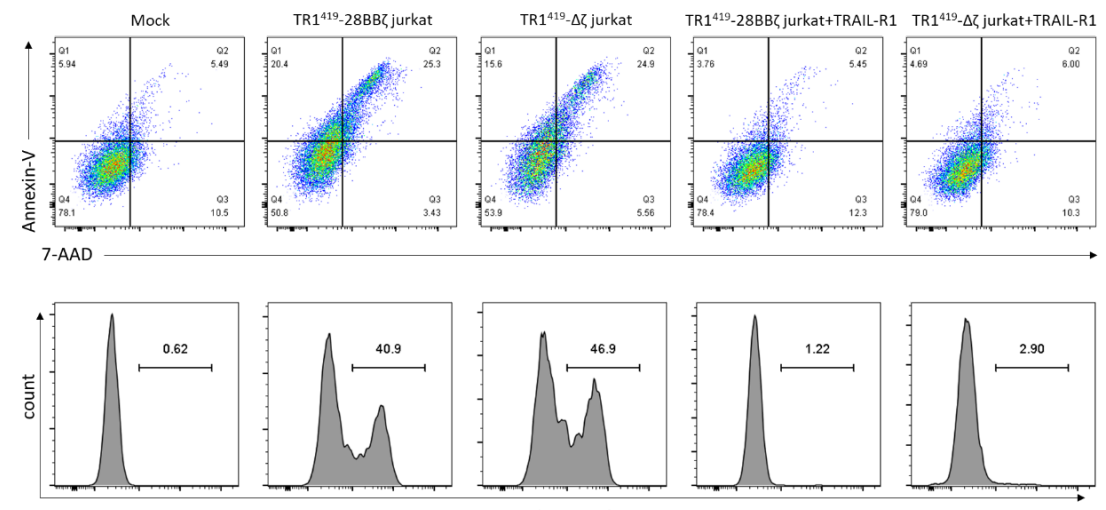

Fig.2. scFv from TR1 $1^{419}$ CAR mediated tumor cell apoptosis by binding with TRAIL-R1. (A) Schematic representation of TR1 $1^{419}[?] \zeta$ and the lentiviral vector. The construct consisted of the extracellular portion

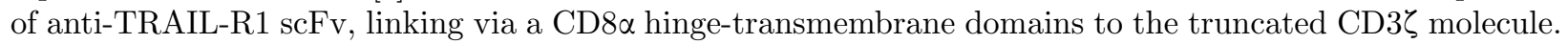
(B) The expression of TR1 $1^{419}-28 \mathrm{BB} \zeta$ and $\mathrm{TR} 1^{419}[?] \zeta$ in Jurkat cells was detected by flow cytometry. (C) Cytotoxicity of TR $1^{419}-28 \mathrm{BB} \zeta$ - and TR $1^{419}[?] \zeta$-Jurkat cells against SW480 in the absence or in the presence of soluble TRAIL-R1 protein was determined by RTCA. The analysis was performed using Students' t tests. Data reflected the mean \pm SEM of triplicate wells, ${ }^{* * *} p<0.01$. (D) SW480 were fixed and labeled with annexin $\mathrm{V}$ and 7 -AAD and then analyzed by flow cytometry to identify apoptotic cells (annexin $\mathrm{V}^{+} / 7-\mathrm{AAD}^{-}$ and annexin $\mathrm{V}^{+} / 7-\mathrm{AAD}^{+}$), after incubation with effector cells for $2 \mathrm{~h}$. (E) The expression of caspase3 protein in SW480 analyzed by flow cytometry, after incubation with effector cells for $2 \mathrm{~h}$.

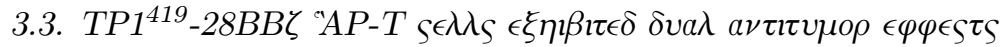


To further investigate whether TR1 ${ }^{419}-28 \mathrm{BB} \zeta \mathrm{CAR}-\mathrm{T}$ cells can mediate tumor apoptosis through binding to death receptor TRAIL-R1, we first generated TRAIL-R1 (full length) and TRAIL-R1 (truncation) lentivirus vectors. The TRAIL-R1 (full length) was composed of full TRAIL-R1, and the death domain of TRAIL-R1 was truncated in the TRAIL-R1 (truncation) [28] (Fig. 3A). We produced 293T (TRAIL-R1 full length) and 293T (TRAIL-R1 trunc) cells by lentiviral transfecting the associated plasmids (Fig. 3B).

Next, we generated TR1 $1^{419}-28 \mathrm{BB} \zeta \mathrm{CAR}-\mathrm{T}$ cells and TR1 ${ }^{419}[?] \zeta-\mathrm{T}$ cells by lentiviral transduction, which transfection rates were detected by flow cytometry (Fig. 3C). Then, we performed cytotoxicity assays using TR1 $1^{419}-28 \mathrm{BB} \zeta \mathrm{CAR}-\mathrm{T}$ cells and TR $1^{419}[?] \zeta-\mathrm{T}$ cells as effector cells, and different $293 \mathrm{~T}$ cells as target cells. As for the TRAIL-R1 negative $293 \mathrm{~T}$ cells, TR $1^{419}$-28BB $\zeta$ CAR-T cells and TR1 ${ }^{419}[?] \zeta-T$ cells had no significant killing effect and secretion of effector cytokines, compared with the mock T cells (Fig. 3DF). The TR $1^{419}-28 \mathrm{BB} \zeta$ CAR-T cells and TR $1^{419}[?] \zeta-T$ cells effectively killed the 293T (TRAIL-R1 full length) cells, whereas TR1 ${ }^{419}-28 \mathrm{BB} \zeta \mathrm{CAR}-\mathrm{T}$ cells displayed significantly higher specific killing compared to TR1 ${ }^{419}[?] \zeta-T$ cells (Fig. 3D). Meanwhile, the data showed that much higher levels of IFN- $\gamma$ and Granzyme B were produced by TR1 $1^{419}$-28BB $\zeta$ CAR-T cells compared to TR $1^{419}[?] \zeta-\mathrm{T}$ cells when co-culturing with $293 \mathrm{~T}$ (TRAIL-R1 full length) cells. However, no significant difference was found in cytokine secretion between TR $1^{419}[?] \zeta-T$ cells and mock $\mathrm{T}$ cells (Fig. 3E-F). As for the $293 \mathrm{~T}$ (TRAIL-R1 trunc) cells, TR1 ${ }^{419}[?] \zeta-\mathrm{T}$ cells had no significant killing effect and secretion of effector cytokines compared with the mock $\mathrm{T}$ cells, but TR $1^{419}-28 \mathrm{BB} \zeta$ CAR-T cells displayed significantly killing effect and IFN- $\gamma$ and Granzyme B production (Fig. 3D-F). The results above suggested that TR $1^{419}$-CAR-T cells can not only effectively induce T-cell mediated cytotoxicity toward tumor cells, but also mediate tumor cell apoptosis through activation of the death receptor-dependent apoptotic pathway, indicating dual anti-tumor activity.

A

TRAIL-R1 Full length

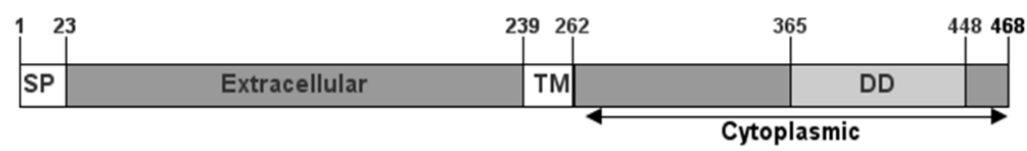

TRAIL-R1 Truncation

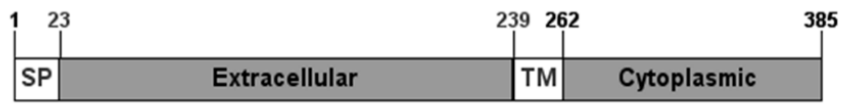

$\mathbf{B}$

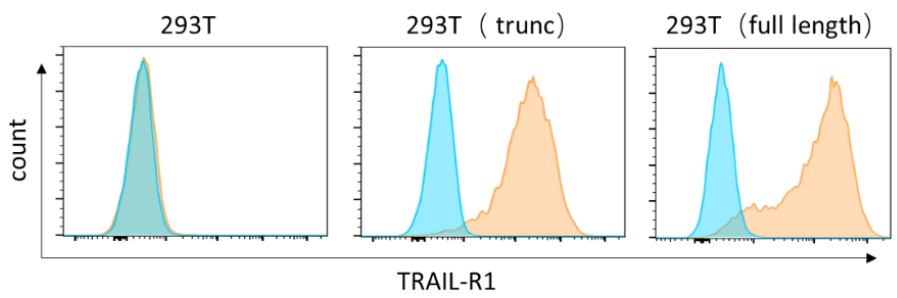

C

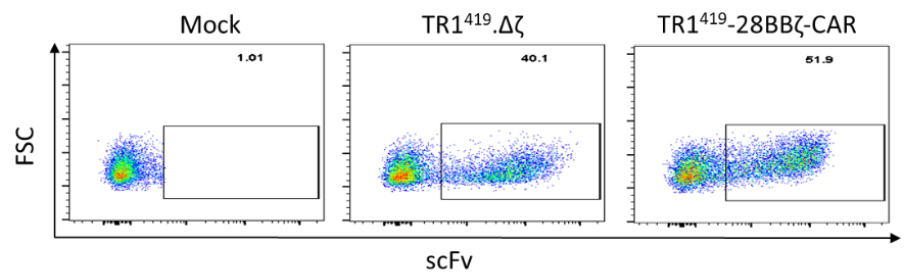


D

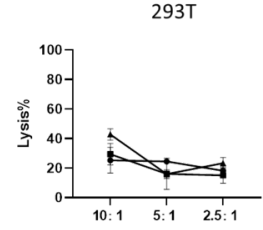

E/T

$\mathbf{E}$

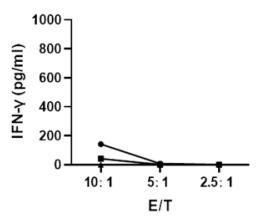

$\mathbf{F}$

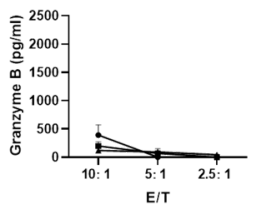

293T ( TRAIL-R1 truncation)

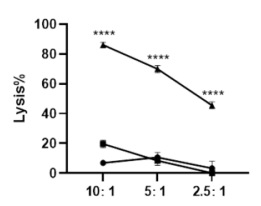

$E / T$
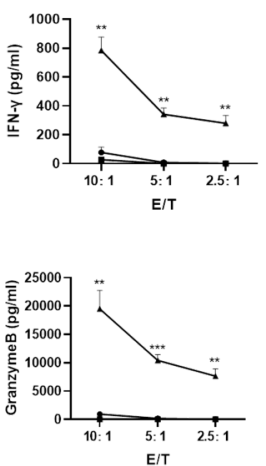

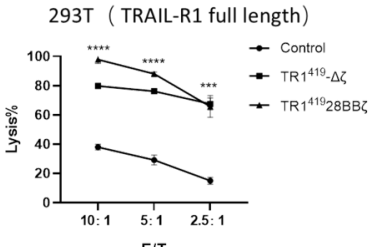

$E / T$
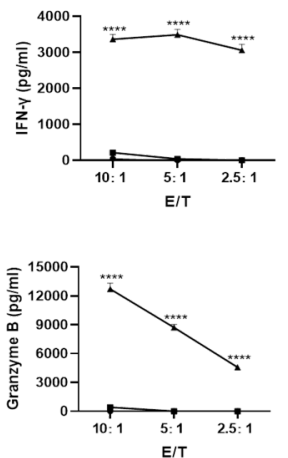

Fig.3.TR1 ${ }^{419}$-28BBל CAR-T cells mediated dual tumour cell killing. (A) Schematic representation of TRAIL-R1 (full length) and TRAIL-R1 (truncation). TRAIL-R1 (full length) comprised the extracellular region, the transmembrane domain, and the intracellular region with death domain. TRAIL-R1 (truncation) comprised the extracellular region, the transmembrane domain, and the intracellular region without death domain, SP: signal peptide, TM: transmembrane domain, DD: death domain. (B) 293T cells were transfected with the lentiviral expression TRAIL-R1 trunc and TRAIL-R1 full length plasmids, respectively. Then, the expression of TRAIL-R1 in 293T cells was determined by flow cytometry. (C) Mock (untransduced), TR1 ${ }^{419}-28 \mathrm{BB} \zeta \mathrm{CAR}-\mathrm{T}$ cells or TR1 $1^{419}[?] \zeta-\mathrm{T}$ cells were evaluated by flow cytometry for scFv expression. (D) Cytotoxic activity of TR1 $1^{419}-28 \mathrm{BB} \zeta \mathrm{CAR}$ - and TR1 $1^{419}$ [?] $\zeta-\mathrm{T}$ cells against 293T, 293T (TRAIL-R1 trunc) and 293T (TRAIL-R1 full length) was determined by RTCA assay. (E, F) IFN- $\gamma$ and Granzyme B production by TR1 $1^{419}-28 \mathrm{BB} \zeta$ CAR-T cells or TR $1^{419}[?] \zeta-T$ cells was detected by ELISA when co-cultured with the indicated cells for $24 \mathrm{~h}$. The analyses were performed using Students' t tests. Data reflected the mean $\pm \mathrm{SEM}$ of three triplicate wells. ${ }^{*} p<0.05,{ }^{* *} p<0.01$ and ${ }^{* * *} p<0.001$.

\subsection{The costimulatory domains did not influence the phenotypes of TR $1^{419}$ - CAR-T cells}

It has been reported that the phenotypic and functional differences of the second and third generation CAR-T cells are related to the selection of target antigen and the design of scFv structure [29,30], which suggested that we should select the most appropriate CARs based on our own scFv structure. To explore which CARs structure is the most appropriate for scFv from TR1 ${ }^{419}$, we first constructed CD28-containing (TR1 $\left.{ }^{419}-28 \zeta\right)$ and 4-1BB-containing (TR1 ${ }^{419}{ }_{-B B}$ B $)$ TR1 ${ }^{419}$-CARs (Fig. 4A). For the following studies, we generated TR1 $1^{419}-28 \zeta, \mathrm{TR} 1^{419}-\mathrm{BB} \zeta$ and $\mathrm{TR} 1^{419}-28 \mathrm{BB} \zeta \mathrm{CAR}-\mathrm{T}$ cells by lentiviral transduction. The surface expression of CAR on the T cells was measured by flow cytometry. Three TR1 $1^{419}$-CARs showed comparable transfection rates and mean fluorescence intensity (Fig. 4B). Meanwhile, TR $1^{419}-28 \zeta$, TR $1^{419}$-BB and TR1 ${ }^{419}$-28BB $\zeta$ CAR-T cells exhibited similar cell surface T cell phenotypes, of which approximately $60 \%$ were Tn (Fig. 4C). CD8 ${ }^{+}$TR $1^{419}-28 \mathrm{BB} \zeta$ CAR-T cells showed higher levels of PD-1 and LAG-3 expression than CD ${ }^{+}{ }^{T R} 1^{419}-28 \zeta$ CAR-T cells. However, CD4 ${ }^{+}$TR $1^{419}-28 \zeta$ CAR-T cells showed higher levels of TIM-3 expression than $\mathrm{CD} 4^{+} \mathrm{TR} 1^{419}-28 \mathrm{BB} \zeta$ CAR-T cells (Figure 4D). (Fig. 4D). 
A

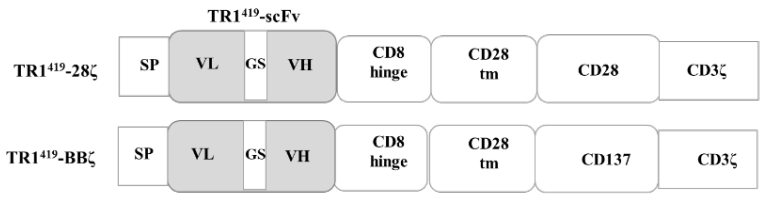

B
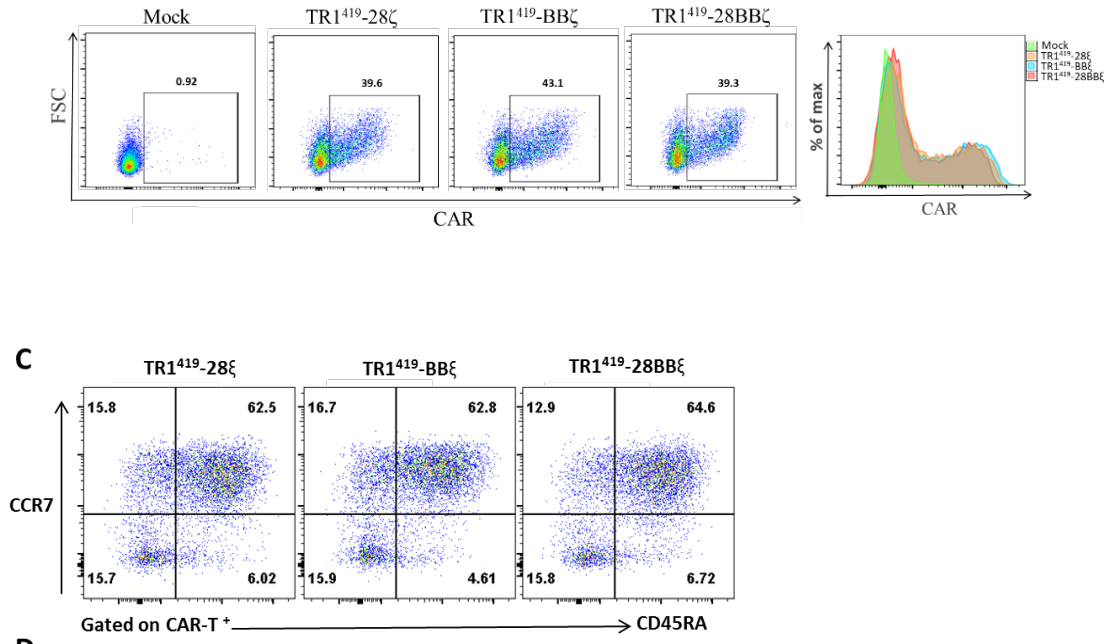

D

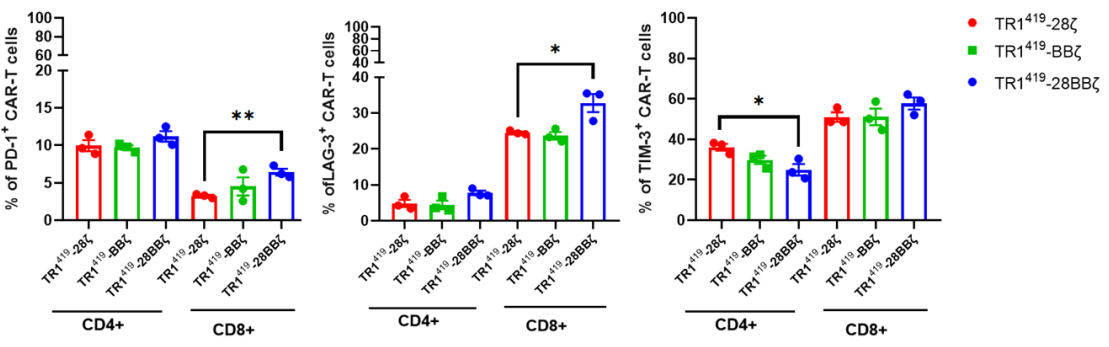

Fig.4. The costimulatory domains did not impact TR $1{ }^{419} \mathrm{CAR}-\mathrm{T}$ phenotypes. (A) Diagram of the lentiviral expression cassette with the second generation TR1 $1^{419}$-CARs containing the humanized scFv (TR1 ${ }^{419}$ ) targeting TRAIL-R1, with a CD8 $\alpha$ hinge domain, a CD28 transmembrane domain, a cytoplasmic CD28 or

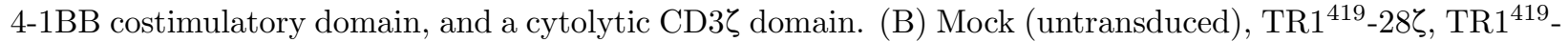
$\mathrm{BB} \zeta$ or $\mathrm{TR} 1^{419}-28 \mathrm{BB} \zeta \mathrm{CAR} T$ cells were evaluated by flow cytometry for scFv expression to detect lentiviral transduction of CARs. (C) Representative CAR-T cell phenotyping plot based on CD45RA and CCR7. $\mathrm{CD}_{4} \mathrm{RA}^{+} \mathrm{CCR}^{+}$: naïve $\mathrm{T}$ cells, CD45RA-CCR7 ${ }^{+}$: central memory T cells, CD45RA ${ }^{-} \mathrm{CCR}^{-}$: effector memory T cells, CD45RA ${ }^{+} \mathrm{CCR}^{-}$: effector T cells. (D) Quantification of inhibitory molecules (PD-1, LAG-3 and TIM-3) expression on $\mathrm{CD} 4^{+} \mathrm{CAR}$ and $\mathrm{CD} 8^{+} \mathrm{CAR} \mathrm{T}$ cells on day 7 following lentiviral transfection. The analyses were performed using Students' t tests. Data reflected the mean \pm SEM of three independent experiments, ${ }^{*} p<0.05,{ }^{* *} p<0.01$.

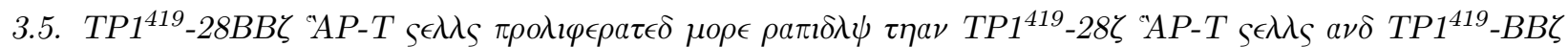

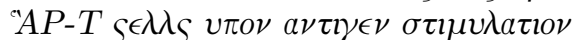

To explore the functional differences among $\mathrm{TR} 1^{419}-28 \zeta$, TR1 $1^{419}$-BB $\zeta$ and TR1 $1^{419}-28 \mathrm{BB} \zeta \mathrm{CAR}-\mathrm{T}$ cells, we first examined the expression of CD137 in TR $1{ }^{419} \mathrm{CAR}-\mathrm{T}$ cells after 24 hours of stimulation with different concentrations of plate-bound recombinant human TRAIL-R1 protein. While TR1 ${ }^{419}{ }_{-2} 28 \zeta_{\text {, TR }}{ }^{419}$ $\mathrm{BB \zeta}$ and TR1 ${ }^{419}-28 \mathrm{BB} \zeta \mathrm{CAR}-\mathrm{T}$ cells exhibited similar CD137 expression against $0.5 \mathrm{ug} / \mathrm{ml}, 0.01 \mathrm{ug} / \mathrm{ml}$ and 
$0.005 \mathrm{ug} / \mathrm{ml}$ antigen protein, TR1 ${ }^{419}-28 \mathrm{BB} \zeta \mathrm{CAR}-\mathrm{T}$ cells induced higher CD137 expression against $0.1 \mathrm{ug} / \mathrm{ml}$ and $0.05 \mathrm{ug} / \mathrm{ml}$ antigen protein (Fig. 5A). Then, we performed in vitro tumor killing assays. TR $1^{419}-28 \zeta$, TR1 ${ }^{419}$-BB $\zeta$ and TR1 $1^{419}-28 \mathrm{BB} \zeta$ CAR-T cells were co-cultured with various tumor targets, and Calcein AM release-based cytotoxic cell assay was used to quantify tumor cell killing. The results showed that TR $1^{419}-28 \zeta$, TR1 ${ }^{419}$-BB $\zeta$ and TR1 $1^{419}-28 \mathrm{BB} \zeta$ CAR-T cells killed TRAIL-R1-expressing tumor cells with similar efficiency (Fig. 5B).

The proliferation of TR1 ${ }^{419}$-CAR-T cells upon antigen stimulation was assessed using CFSE staining, and the CFSE fluorescence declined following each cell division. The expression CFSE of TR $1^{419}$-CAR-T cells was detected after co-cultured with TRAIL-R1 positive SW480 cells for 7 days. TR1 ${ }^{419}{ }^{2} 28 B B \zeta$ CAR-T cells showed superior expansion compared with TR1 $1^{419}-28 \zeta$ and TR $1^{419}$-BB $\zeta$ CAR-T cells against TRAILR1 positive tumors, and no significant difference was found in cell proliferation between TR $1^{419}-28 \zeta$ and TR1 ${ }^{419}$-BBלCAR-T cells (Fig. 5C). Meanwhile, we also detected the expression of PD- 1 in TR $1{ }^{419}$ CAR$\mathrm{T}$ cells after co-incubation with SW480. The results indicated that PD-1 was more frequently expressed by TR1 $1^{419}-28 \mathrm{BB} \zeta \mathrm{CAR}-\mathrm{T}$ cells than TR1 $1^{419}-28 \zeta$ and TR1 ${ }^{419}-\mathrm{BB} \zeta \mathrm{CAR}-\mathrm{T}$ cells. However, the frequencies of PD- $1^{+}$CAR-T cells between TR1 $1^{419}-28 \zeta$ and TR1 $1^{419}-\mathrm{BB} \zeta$ groups were similar (Fig. 5D). There has shown that the highest level of PD-1 expression reflects T-cell exhaustion status [31]. Thus, based on positive PD-1 expression, PD- $1^{+} \mathrm{TR} 1{ }^{419} \mathrm{CAR}-\mathrm{T}$ cells were divided into two subgroups: high PD-1 expressing cells $\left(\mathrm{PD}-1^{\text {high }}\right)$ and low PD-1 positive cells $\left(\mathrm{PD}-1^{\text {low }}\right)$. There was no significant difference in the expression of PD- $1^{\text {low }}$ among the TR $1^{419}-28 \zeta, \mathrm{TR} 1^{419}-\mathrm{BB} \zeta$ and TR $1^{419}-28 \mathrm{BB} \zeta \mathrm{CAR}-\mathrm{T}$ cells. However, PD- $1^{\text {high }}$ was more frequently expressed by TR1 $1^{419}-28 \mathrm{BB} \zeta \mathrm{CAR}-\mathrm{T}$ cells than TR ${ }^{419}$-BBלCAR-T cells (Fig. 5E). In summary, TR1 $1^{419}-28 \mathrm{BB} \zeta$ CAR-T cells proliferated more rapidly than TR $1^{419}-28 \zeta$ CAR-T cells and TR $1^{419}$-BBל CAR$\mathrm{T}$ cells upon antigen stimulation, but expressed higher levels of PD-1.

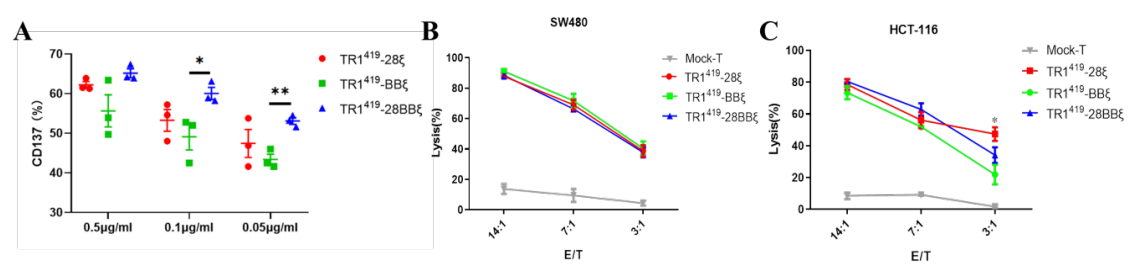


D

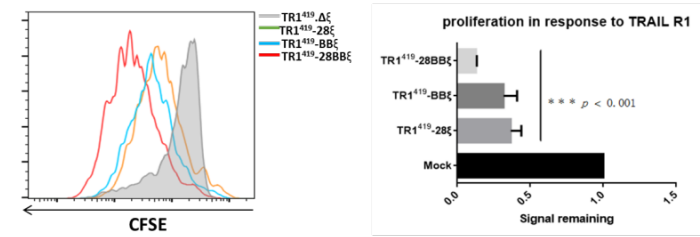

E

Mock

$\operatorname{TR} 1^{419}-28 \xi$

$\mathrm{TR} 1^{419-\mathrm{BB} \xi}$
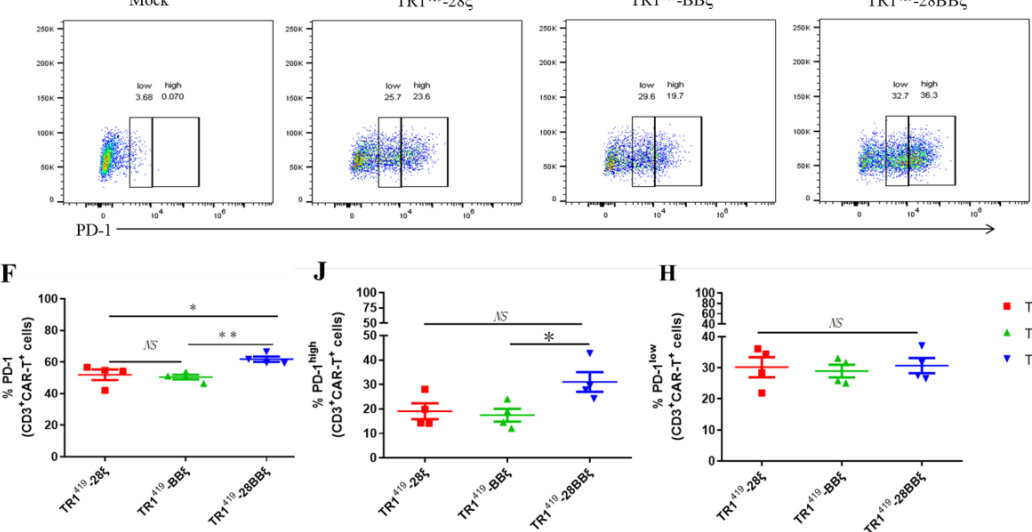

H

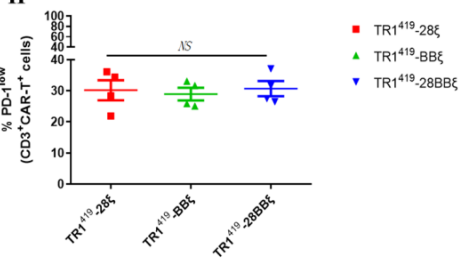

Fig.5.TR1 ${ }^{419}-28 \mathrm{BB} \zeta$ CAR-T cells showed greater antigen-specific expansion compared with TR1 ${ }^{419}-28 \zeta$ CAR-T cells and TR1 ${ }^{419}$-BBל CAR-T cells. (A) Expression of CD137 on TR $1{ }^{419}$ CAR-T cells was detected by flow cytometry cultured overnight on plate-bound recombinant human TRAIL-R1 at varying protein concentrations. (B, C) Cytotoxic activity of TR $1^{419}-28 \zeta$ CAR, TR $1^{419}$-BB $\zeta$ CAR or TR1 ${ }^{419}-28 \mathrm{BB} \zeta \mathrm{CAR} \mathrm{T}$ cells against TRAIL-R1 positive tumor cell lines (SW480 and HCT116). The effector cells were co-cultured for $6 \mathrm{~h}$ with target cells at E:T ratio of 14:1, 7:1 and 3:1, respectively. Cytotoxicity was determined by Calcein AM release-based cytotoxic cell assay. The analysis was performed using Students' t tests. Data reflected the mean \pm SEM of three triplicate wells, ${ }^{*} p<0.05$. (D) TR $1{ }^{419} \mathrm{CAR} T$ cell proliferation indicated by division of CFSE was assessed by flow cytometry. TR $1^{419}-28 \zeta$ CAR, TR $1^{419}$-BB $\zeta$ CAR and TR $1^{419}-28 B B \zeta$ CAR T cells were stained with CFSE, respectively. Then, TR $1{ }^{419} \mathrm{CAR}$ T cells were cultured with SW480 for $7 \mathrm{~d}$, and analyzed by flow cytometry. (E-H) Expression of PD-1 on TR $1{ }^{419} \mathrm{CAR}$ T cells was analyzed by FACS after 7 days of co-culture with tumor cells. TR $1{ }^{419} \mathrm{CAR} T$ cells were classified as PD-1 negative, PD-1low and PD-1high expressing sub-populations. The analyses were performed using Students' $t$ tests. Data reflected the mean \pm SEM of three independent experiments, ${ }^{*} p<0.05,{ }^{* *} p<0.01$.

\section{Discussion}

In the present work, we demonstrated that TR $1^{419}$-based CAR-T cells had potent dual anti-tumor activities in vitro. On the one hand, TR $1{ }^{419} \mathrm{CAR}$ can mediate tumor cell apoptosis through activation of the death receptor-dependent apoptotic pathway. On the other hand, TR $1{ }^{419} \mathrm{CAR}$ can effectively induce T-cell mediated cytotoxicity by inducing multiple signals with the binding of TRAIL-R1. Meanwhile, by comparing phenotype and function between the second- and third-generation TR $1{ }^{419} \mathrm{CAR}-\mathrm{T}$ cells, the third-generation TR1 ${ }^{419}$-28BB $\zeta$ CAR-T cells showed higher sensitivity to target antigen, proliferated more rapidly and expressed higher levels of PD-1 upon antigen stimulation.

Previously, we developed fully human TR $1^{419}$-IgG with tumoricidal activity, but this antibody required additional crosslinking antibodies to induce apoptosis in the target cells [32]. We demonstrated that the $\mathrm{scFv}$ from TR $1^{419}$ designed into CAR structure can directly mediate tumor apoptosis by binding to TRAIL$\mathrm{R} 1$ in the absence of additional crosslinking antibodies. The underlying mechanism of cell apoptosis induced by $\mathrm{scFv}$ from TR $1^{419}$ may be related to the spatial structure of the TR $1^{419} \mathrm{CAR}$. The specific mechanism still requires further research and investigation. 
Currently, the clinical efficacy of CAR-T cells in hematological malignancies is rarely achieved in solid tumors, and the factors necessary for improving its efficacy are currently being determined [33,34]. Combinations with other treatments will be a promising strategy to improve the efficacy of CAR-T cells on solid tumors [35]. In our study, TR1 ${ }^{419}$-based CAR-T cells had potent dual anti-tumor activities. The induction of apoptotic signals from TR1 on the target cells was equivalent to that of other therapies in this case. However, the apoptotic signals from TR1 are targeted, unlike chemotherapy and radiotherapy, without inducing localized immune cell damage [36]. Moreover, TR1-mediated tumor cell apoptosis can induce immunogenic cell death of tumor cells which enhances antigen presentation and antitumor immune responses.

Although, the role of costimulatory signals in CAR-T development is well-established, the optimal costimulatory domains for CAR-T cells remains to be defined, and should be evaluated case-by-case in order to fine-tune immunotherapy approaches $[37,38]$. Literature reported that the choice of 4-1BB signaling domain in CARs conferred improved selectivity for higher tumor antigen density, reduced $\mathrm{T}$ cell exhaustion phenotype and reduced basal T-cell activation $[39,40]$. In our research, there was no significant difference in phenotypes and function between the TR1 $1^{419}-28 \zeta$ and TR $1^{419}-28 \mathrm{BB} \zeta$ CAR-T cells. However, the thirdgeneration TR1 $1^{419}-28 \mathrm{BB} \zeta \mathrm{CAR}-\mathrm{T}$ cells showed higher sensitivity to target antigen and proliferated more rapidly upon antigen stimulation. The incongruent results may have the following reasons: 1) the various preparation methods and experimental conditions, 2) the various $\mathrm{scFv}$ domains, 3) the various other components of CARs.

There are some limitations in our study that requires further acknowledgement. Further and more comprehensive studies are required to confirm these findings. And additional in vivo experiments are needed to verify the results of the above in vitro. Lastly, the safety issues related to off-tumor toxicity also needs further studies to address. In conclusion, we designed and demonstrated that TR $1{ }^{419} \mathrm{CAR}-\mathrm{T}$ cells can mediate dual tumor cell killing, and the third-generation TR1 ${ }^{419} 28 \mathrm{BBCAR}-\mathrm{T}$ cells exhibited a higher sensitivity at low antigen, and proliferated more rapidly upon antigen stimulation, compared to the second-generation TR $1{ }^{419}$ CAR-T cells. This dual killing mechanism provides a novel strategy for other CARs design.

\section{Author Contributions:}

Aishun Jin: Conceptualization, Supervision, Project administration. YN and LD: Investigation, Methodology, Writing - original draft preparation: MS andJH: Methodology, Project administration TL: Software, Methodology. FL : Software, Data curation,Bioinformatics analysis. XH: Writing-review and Editing.LD: Formal analysis, Investigation, Resources. MS:Investigation, Formal analysis. DP: Supervision.

\section{Funding:}

This work was supported by National Natural Science Foundation of China, grant number 81572807 and 81872329; and by Chongqing Municipal Education Commission of Science and Technology Research Project of China, grant number: KJZD-K201800403

\section{Acknowledgements:}

We would like to thank all team members involved in tumor immunotherapy project at Chongqing Key Laboratory of Basic and Translational Research of Tumor Immunology, Chongqing Medical University for their technological assistance and help in developing this article. We thank Professor Tatsuhiko Ozawac, Eiji

Kobayashic and Hiroyuki Kishi for help with experiments. We also thank all healthy individuals participated in this study. We appreciate supporter Mr. Yuling Feng providing Chongqing Medical University fund (X4457).

\section{Conflict of Interests}

The authors declare no competing interests.

\section{References}

1. J.A. Figueroa, A. Reidy, L. Mirandola, K. Trotter, N. Suvorava, A. Figueroa, V. Konala, A. Aulakh, 
L. Littlefield, F. Grizzi, R.L. Rahman, M.R. Jenkins, B. Musgrove, S. Radhi, N. D'Cunha, L.N. D'Cunha, P.L. Hermonat, E. Cobos, M. Chiriva-Internati, Chimeric antigen receptor engineering: a right step in the evolution of adoptive cellular immunotherapy, Int. Rev. Immunol. 34 (2015) 154-187. https://doi.org/10.3109/ 08830185.2015.1018419.

2. V. Hillerdal, M. Essand, Chimeric antigen receptor-engineered T cells for the treatment of metastatic prostate cancer, Biodrugs 29 (2015) 75-89. https://doi.org/10.1007/ s40259-015-0122-9.

3. W. Zhang, CAR T-cell therapy: opportunities and challenges, Immunotherapy 8 (2016) 245-247. https://doi.org/10.2217/imt.15.129.

4. C.H. June, R.S. O'Connor, O.U. Kawalekar, S. Ghassemi, M.C. Milone, CAR T cell immunotherapy for human cancer, Science 359 (2018) 1361-1365. https://doi.org/ 10.1126/science.aar6711.

5. D.W. Lee, J.N. Kochenderfer, M. Stetler-Stevenson, Y.K. Cui, C. Delbrook, S.A. Feldman, T.J. Fry, R. Orentas, M. Sabatino, N.N. Shah, S.M. Steinberg, D. Stroncek, N. Tschernia, C. Yuan, H. Zhang, L. Zhang, S.A. Rosenberg, A.S. Wayne, C.L. Mackall, T cells expressing CD19 chimeric antigen receptors for acute lymphoblastic leukaemia in children and young adults: a phase 1 dose-escalation trial, Lancet 385 (2015) 517-528. https://doi.org/10.1016/s0140-6736(14)61403-3.

6. J. Liu, J.F. Zhong, X. Zhang, C. Zhang, Allogeneic CD19-CAR-T cell infusion after allogeneic hematopoietic stem cell transplantation in B cell malignancies, J. Hematol. Oncol. 10 (2017) 35. https://doi.org/10.1186/s13045-017-0405-3.

7. S. Stoiber, B.L. Cadilha, M.-R. Benmebarek, S. Lesch, S. Endres, S. Kobold, Limitations in the Design of Chimeric Antigen Receptors for Cancer Therapy, Cells 8 (2019). https://doi.org/10.3390/cells8050472.

8. T.T. Byrd, K. Fousek, A. Pignata, C. Szot, H. Samaha, S. Seaman, L. Dobrolecki, V.S. Salsman, H.Z. Oo, K. Bielamowicz, D. Landi, N. Rainusso, J. Hicks, S. Powell, M.L. Baker, W.S. Wels, J. Koch, P.H. Sorensen, B. Deneen, M.J. Ellis, M.T. Lewis, M. Hegde, B.S. Fletcher, B. St Croix, N. Ahmed, TEM8/ANTXR1-Specific CAR T Cells as a Targeted Therapy for Triple-Negative Breast Cancer, Cancer Res. 78 (2018) 489-500. https://doi.org/10.1158/0008-5472.Can-16-1911.

9. H. Du, K. Hirabayashi, S. Ahn, N.P. Kren, S.A. Montgomery, X. Wang, K. Tiruthani, B. Mirlekar, D. Michaud, K. Greene, S.G. Herrera, Y. Xu, C. Sun, Y. Chen, X. Ma, C.R. Ferrone, Y. Pylayeva-Gupta, J.J. Yeh, R. Liu, B. Savoldo, S. Ferrone, G. Dotti, Antitumor Responses in the Absence of Toxicity in Solid Tumors by Targeting B7-H3 via Chimeric Antigen Receptor T Cells, Cancer Cell 35 (2019) 221-237 e228. https://doi.org/10.1016/j.ccell.2019.01.002.

10. M.C. Ramello, I. Benzaïd, B.M. Kuenzi, M. Lienlaf-Moreno, W.M. Kandell, D.N. Santiago, M. PabónSaldaña, L. Darville, B. Fang, U. Rix, S. Yoder, A. Berglund, J.M. Koomen, E.B. Haura, D. AbateDaga, An immunoproteomic approach to characterize the CAR interactome and signalosome, Science Signaling 12 (2019) eaap9777. https://doi.org/10.1126/scisignal.aap9777.

11. C. Sun, P. Shou, H. Du, K. Hirabayashi, Y. Chen, L.E. Herring, S. Ahn, Y. Xu, K. Suzuki, G. Li, O. Tsahouridis, L. Su, B. Savoldo, G. Dotti, THEMIS-SHP1 Recruitment by 4-1BB Tunes LCKMediated Priming of Chimeric Antigen Receptor-Redirected T Cells, Cancer Cell 37 (2020) 216-225.e6. https://doi.org/10.1016/j.ccell.2019.12.014.

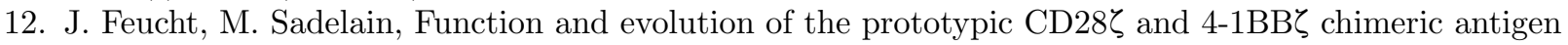
receptors, Immuno-Oncology Technology 8 (2020) 2-11. .

13. S. Guedan, A.D. Posey, Jr., C. Shaw, A. Wing, T. Da, P.R. Patel, S.E. McGettigan, V. CasadoMedrano, O.U. Kawalekar, M. Uribe-Herranz, D. Song, J.J. Melenhorst, S.F. Lacey, J. Scholler, B. Keith, R.M. Young, C.H. June, Enhancing CAR T cell persistence through ICOS and 4-1BB costimulation, JCI Insight 3 (2018) e96976. https://doi.org/10.1172/jci.insight.96976.

14. S.J. Priceman, E.A. Gerdts, D. Tilakawardane, K.T. Kennewick, J.P. Murad, A.K. Park, B. Jeang, Y. Yamaguchi, X. Yang, R. Urak, L. Weng, W.-C. Chang, S. Wright, S. Pal, R.E. Reiter, A.M. Wu, C.E. Brown, S.J. Forman, Co-stimulatory signaling determines tumor antigen sensitivity and persistence of CAR T cells targeting PSCA+ metastatic prostate cancer, Oncoimmunology 7 (2017) e1380764e1380764. https://doi.org/ 10.1080/2162402X.2017.1380764.

15. S.R. Wiley, K. Schooley, P.J. Smolak, W.S. Din, C.P. Huang, J.K. Nicholl, G.R. Sutherland, T.D. 
Smith, C. Rauch, C.A. Smith, et al., Identification and characterization of a new member of the TNF family that induces apoptosis, Immunity 3 (1995) 673-682. https://doi.org/10.1016/10747613(95)90057-8.

16. D.I. Radke, Q. Ling, R. Häsler, G. Alp, H. Ungefroren, A. Trauzold, Downregulation of TRAILReceptor 1 Increases TGF $\beta$ Type II Receptor Expression and TGF $\beta$ Signalling Via MicroRNA-370-3p in Pancreatic Cancer Cells, Cancers (Basel) 10 (2018) 399. https://doi.org/10.3390/cancers10110399.

17. A.W. Tolcher, M. Mita, N.J. Meropol, M. von Mehren, A. Patnaik, K. Padavic, M. Hill, T. Mays, T. McCoy, N.L. Fox, W. Halpern, A. Corey, R.B. Cohen, Phase I pharmacokinetic and biologic correlative study of mapatumumab, a fully human monoclonal antibody with agonist activity to tumor necrosis factor-related apoptosis-inducing ligand receptor-1, J. Clin. Oncol. 25 (2007) 1390-1395. .

18. J. Shi, J. Li, Z. Xu, L. Chen, R. Luo, C. Zhang, F. Gao, J. Zhang, C. Fu, Celastrol: A Review of Useful Strategies Overcoming its Limitation in Anticancer Application, Front. Pharmacol. 11 (2020) 558741. https://doi.org/10.3389/fphar.2020.558741.

19. A. Jin, T. Ozawa, K. Tajiri, Z. Lin, T. Obata, I. Ishida, H. Kishi, A. Muraguchi, Generation of TRAIL-receptor 1-specific human monoclonal $\mathrm{Ab}$ by a combination of immunospot array assay on a chip and human Ab-producing mice, Eur. J. Immunol. 40 (2010) 3591-3593. https://doi.org/10.1002/eji.201040551.

20. S. Kaveri, T. Ozawa, X. Piao, E. Kobayashi, Y. Zhou, H. Sakurai, T. Andoh, A. Jin, H. Kishi, A. Muraguchi, A Novel Rabbit Immunospot Array Assay on a Chip Allows for the Rapid Generation of Rabbit Monoclonal Antibodies with High Affinity, PLoS ONE 7 (2012) e52383. https://doi.org/10.1371/journal.pone.0052383.

21. Z. Hao, X. Han, X. Sun, M. Shen, J. Huang, Y. Li, T. Ozawa, D. Pang, S. Jin, H. Kishi, A. Muraguchi, A. Jin, Fully human monoclonal antibodies to TRAIL-R1 enhance TRAIL-induced apoptosis via activation of caspase-8 pathway, Biochem. Biophys. Res. Commun. 475 (2016) 238-244. https://doi.org/10.1016/j.bbrc.2016.05.089.

22. H. Wajant, D. Moosmayer, T. Wüest, T. Bartke, E. Gerlach, U. Schönherr, N. Peters, P. Scheurich, K. Pfizenmaier, Differential activation of TRAIL-R1 and -2 by soluble and membrane TRAIL allows selective surface antigen-directed activation of TRAIL-R2 by a soluble TRAIL derivative, Oncogene 20 (2001) 4101-4106. https://doi.org/10.1038/ sj.onc.1204558.

23. F. Dufour, T. Rattier, A.A. Constantinescu, L. Zischler, A. Morlé, H. Ben Mabrouk, E. Humblin, G. Jacquemin, E. Szegezdi, F. Delacote, N. Marrakchi, G. Guichard, C. Pellat-Deceunynck, P. Vacher, P. Legembre, C. Garrido, O. Micheau, TRAIL receptor gene editing unveils TRAIL-R1 as a master player of apoptosis induced by TRAIL and ER stress, Oncotarget 8 (2017) 9974-9985. https://doi.org/10.18632/oncotarget.14285.

24. G. Gross, T. Waks, Z. Eshhar, Expression of immunoglobulin-T-cell receptor chimeric molecules as functional receptors with antibody-type specificity, Proc. Natl. Acad. Sci. U. S. A. 86 (1989) 1002410028. https://doi.org/10.1073/pnas.86.24.10024.

25. B.A. Irving, A. Weiss, The cytoplasmic domain of the T-cellreceptor zeta-chain is sufficient to couple to receptor-associated singal transduction pathways, Cell 64 (1991) 891-901. https://doi.org/10.1016/0092-8674(91)90314-o.

26. B. Jonsson, G. Liminga, K. Csoka, H. Fridborg, S. Dhar, P. Nygren, R. Larsson, Cytotoxic activity of calcein acetoxymethyl ester (Calcein/AM) on primary cultures of human haematological and solid tumours, Eur. J. Cancer 32a (1996) 883-887. https://doi.org/10.1016/0959-8049(96)00015-9.

27. M. Bilandzic, A. Rainczuk, E. Green, N. Fairweather, T.W. Jobling, M. Plebanski, A.N. Stephens, Keratin-14 (KRT14) Positive Leader Cells Mediate Mesothelial Clearance and Invasion by Ovarian Cancer Cells, Cancers (Basel) 11 (2019) 1228. https://doi.org/10.3390/cancers11091228.

28. P. Schneider, J.L. Bodmer, M. Thome, K. Hofmann, N. Holler, J. Tschopp, Characterization of two receptors for TRAIL, FEBS Lett. 416 (1997) 329-334. https://doi.org/10.1016/s0014-5793(97)01231-3.

29. S.-Y. Park, H.-H. Park, S.-Y. Park, S.M. Hong, S. Yoon, M.J. Morgan, Y.-S. Kim, Reduction in MLKLmediated endosomal trafficking enhances the TRAIL-DR4/5 signal to increase cancer cell death, Cell Death. Dis. 11 (2020) 744-744. https://doi.org/ 10.1038/s41419-020-02941-9. 
30. D. Wang, Y. Shao, X. Zhang, G. Lu, B. Liu, IL-23 and PSMA-targeted duo-CAR T cells in Prostate Cancer Eradication in a preclinical model, J. Transl. Med. 18 (2020) 23-23. https://doi.org/10.1186/s12967-019-02206-w.

31. R. Saleh, S.M. Toor, D. Al-Ali, V. Sasidharan Nair, E. Elkord, Blockade of PD-1, PD-L1, and TIM-3 Altered Distinct Immune- and Cancer-Related Signaling Pathways in the Transcriptome of Human Breast Cancer Explants, Genes (Basel) 11 (2020) 703. https://doi.org/10.3390/genes11060703.

32. M. Siegemund, O. Seifert, M. Zarani, T. Džinić, V. De Leo, D. Göttsch, S. Münkel, M. Hutt, K. Pfizenmaier, R.E. Kontermann, An optimized antibody-single-chain TRAIL fusion protein for cancer therapy, MAbs 8 (2016) 879-891. https://doi.org/10.1080/ 19420862.2016.1172163.

33. S. Rafiq, O.O. Yeku, H.J. Jackson, T.J. Purdon, D.G. van Leeuwen, D.J. Drakes, M. Song, M.M. Miele, Z. Li, P. Wang, S. Yan, J. Xiang, X. Ma, V.E. Seshan, R.C. Hendrickson, C. Liu, R.J. Brentjens, Targeted delivery of a PD-1-blocking scFv by CAR-T cells enhances anti-tumor efficacy in vivo, Nat. Biotechnol. 36 (2018) 847-856. https://doi.org/10.1038/nbt.4195.

34. C. Tong, Y. Zhang, Y. Liu, X. Ji, W. Zhang, Y. Guo, X. Han, D. Ti, H. Dai, C. Wang, Q. Yang, W. Liu, Y. Wang, Z. Wu, W. Han, Optimized tandem CD19/CD20 CAR-engineered T cells in refractory/relapsed B-cell lymphoma, Blood 136 (2020) 1632-1644. https://doi.org/10.1182/blood.2020005278.

35. K. Adachi, Y. Kano, T. Nagai, N. Okuyama, Y. Sakoda, K. Tamada, IL-7 and CCL19 expression in CAR-T cells improves immune cell infiltration and CAR-T cell survival in the tumor, Nat. Biotechnol. 36 (2018) 346-351. https://doi.org/10.1038/nbt.4086.

36. S. Voigt, S. Philipp, P. Davarnia, S. Winoto-Morbach, C. Röder, C. Arenz, A. Trauzold, D. Kabelitz, S. Schütze, H. Kalthoff, D. Adam, TRAIL-induced programmed necrosis as a novel approach to eliminate tumor cells, BMC Cancer 14 (2014) 74. https://doi.org/ 10.1186/1471-2407-14-74.

37. A.C. Boroughs, R.C. Larson, B.D. Choi, A.A. Bouffard, L.S. Riley, E. Schiferle, A.S. Kulkarni, C.L. Cetrulo, D. Ting, B.R. Blazar, S. Demehri, M.V. Maus, Chimeric antigen receptor costimulation domains modulate human regulatory T cell function, JCI insight 5 (2019) e126194. https://doi.org/10.1172/jci.insight.126194 .

38. X. Meng, R. Jing, L. Qian, C. Zhou, J. Sun, Engineering Cytoplasmic Signaling of

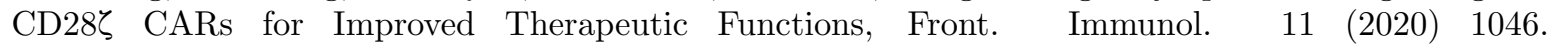
https://doi.org/10.3389/fimmu.2020.01046.

39. S. Guedan, A.D. Posey, Jr., C. Shaw, A. Wing, T. Da, P.R. Patel, S.E. McGettigan, V. CasadoMedrano, O.U. Kawalekar, M. Uribe-Herranz, D. Song, J.J. Melenhorst, S.F. Lacey, J. Scholler, B. Keith, R.M. Young, C.H. June, Enhancing CAR T cell persistence through ICOS and 4-1BB costimulation, JCI insight 3 (2018) e96976. https://doi.org/10.1172/jci.insight.96976.

40. G. Li, J.C. Boucher, H. Kotani, K. Park, Y. Zhang, B. Shrestha, X. Wang, L. Guan, N. Beatty, D. Abate-Daga, M.L. Davila, 4-1BB enhancement of CAR T function requires NF- $x$ B and TRAFs, JCI insight 3 (2018) e121322. https://doi.org/10.1172/ jci.insight.121322. 